\title{
ANATOMIA FOLIAR DE PEDRA-HUME-CAÁ (Myrcia sphaerocarpa, Myrcia guianensis, Eugenia punicifolia - MYRTACEAE)
}

\author{
Luzia I. F. JORGE '; Jaime P. L. AGUIAR 2; Maria de Lourdes P. SILVA'
}

RESUMO - As folhas de Myrcia multiflora (Lam.) DC., Myrcia guianensis (Aubl.) Urb. e Eugenia punicifolia (H.B.K.) DC. são anatômica e morfologicamente descritas. As espécies revelaram diversos elementos histológicos universais para a família, bem como peculiares das mesmas e importantes para orientar a diagnose desses vegetais e para o reconhecimento de fraudes, que ocorrem através de substituições intencionais ou não. Entre os elementos histológicos caracteristicos, destacam-se: ornamentações de cuticula foliar, tipos de estómatos, tipos de contornos celulares das células epidérmicas em vista facial, tipo e abundância relativa de inclusões celulares inorgânicas.

Palavras-chave: Myrcia sphaerocarpa, Eugenia punicifolia, Myrcia guianensis, morfologia foliar, anatomia foliar.

Foliar Anatomy of Pedra-hume-caá (Myrcia sphaerocarpa, Myrcia guianensis, Eugenia punicifolia, Myrtaceae)

ABSTRACT - The anatomy and morphology of the leaves of Myrcia multiflora (Lam.) DC., Myrcia guianensis (Aubl) Urb. and of Eugenia punicifolia (H.B.K.) DC. are described. Although these species show the universal characteristics of the Myrtaceae, they also present some peculiarities that allow their identification and the recognition of fraud, intentional or not. The main characteristic histological elements of these species are: ornamentation of the cuticle, stomata types, outline of epidermal cells in surface view and types and comparative abundance of inorganic cellular inclusions.

Key-words: Myrcia sphaerocarpa, Eugenia punicifolia, Myrcia guianensis, leaf morphology, leaf anatomy

\section{INTRODUÇÃO}

A familia Myrtaceae é uma das mais caracteristicas da flora brasileira, apresentando potencial e significativo interesse econômico para o Brasil. Entre suas espécies são encontrados vegetais medicinais, ornamentais, produtores de madeiras e de frutos comestiveis. A familia compreende cerca de 3500 espécies distribuídas em aproximadamente 100 gêneros, que apresentam dois grandes centros de dispersão: a América tropical e a Austrália (Barroso, 1984).

As plantas conhecidas como "pedra-hume-caá" são indicadas no tratamento da diabete, segundo conhecimento empírico indígena $\mathrm{e}$ africano, que tanta influencia exerceu na formação da cultura brasileira (Almeida, 1993; Conceição, 1982; Cruz, 1982; Pio Correa, 1926). Sào mais comumente relacionadas as seguintes espécies, como sendo pedrahume-caá: Myrcia sphaerocarpa DC., Eugenia punicifolia (HBK) DC., Myrcia citrifolia (Lam.) DC. e Myrcia guianensis (Aubl) Urb. A espécie Myrcia citrifolia não foi estudada neste trabalho porque não foi encontrada nos locais visitados para coleta.

A associação de pedra-hume-caá

'IAL Laboratório I de Santos, Rua Silva Jardim, 90, Macuco, Santos, SP, Brasil - 11015-020. ${ }^{2}$ INPA, Alameda Cosme Ferreira, 1756, Aleixo, Manaus, Amazonas, Brasil - 69083-030. 
com pau-ferro proprociona terapêutica eficaz no tratamento da diabetes (Conceição, 1982). Emprega-se o decocto das folhas. Essa planta é chamada de insulina vegetal. O decocto tanto das folhas como da raízes é útil nos casos de diarréia, enterite, hemorragia e aftas (Almeida, 1993). Enfïm, o vegetal tem aplicação em todos os pacientes que se beneficiam de sua ação antisséptica.

Estudos farmacológicos com Myrcia citrifolia e Myrcia sphaerocarpa evidenciaram ações hipoglicemiante, diurética, hipotensora e antagonista da bradicinina (Mors \& Grune, 1978). São repetidas as referências populares verbais acerca da ação hipoglícemiante de Eugenia punicifolia, porém não foram encontrados estudos farmacológicos que comprovassem cientificamente esse efeito. O gênero Myrcia parece apresentar amplo espectro de atividades farmacológicas, abrangendo também ação anti-tumoral observada para Myrcia fallax (Hecht, 1984) e anti-microbiana (mais anti-fúngica do que anti-bacteriana) confirmada para Myrcia acris (Nadal, 1959).

As Myrtaceae, de um modo geral, são de difícil identificação, e mesmo mateiros experientes podem se enganar, tomando uma espécie por outra. Este trabalho tem por objetivo contribuir para o esclarecimento dessas dúvidas, discutindo conjunta e comparativamente as características organográficas e histológicas das espécies conhecidas como pedra-humecaá.

\section{MATERIAL E MÉTODOS}

São descritas neste trabalho folhas adultas e frescas, que tiveram as seguintes procedências:

Eugenia punicifolia (H.B.K.) DC, - Bosque do INPA, Manaus, AM, Brasil. Coletor: Jaime P. L. Aguiar.

Eugenia of punicifolia (H.B.K.) DC - Estrada de Manaus-Itacotiara, Km 198, município de Itacotiara (campos do Pereu, confluência do rio Pereu), AM, Brasil. Capoeira de transição, campina com afloramento arenoso. Coletores: José F. Ramos e Jaime Paiva Lopes Aguiar, herbário INPA n ${ }^{\circ} 191774$.

Myrcia guianensis (Aubl.) Urb. material de herbário, coletado no municipio de Alter do Chão, PA, Brasil. Coletor: Branch, L. C., $\mathrm{n}^{\circ}$ de herbário INPA 106352.

Myrcia sphaerocarpa (ou multiflora) DC. - Rua Simão-Bianchini, S. Paulo, SP, Brasil. Coletora: Maria Lúcia Kawasaki, ${ }^{\circ}$ de herbário Instituto de Botânica 306966.

Procedeu-se ao estudo da morfologia externa à vista desarmada ou com auxilio de lupa estereoscópica ( 8 a 40 vezes de aumento) segundo Foster \& Gifford (1974). O estudo morfológico interno (anatômico), realizado segundo Oliveira \& Akisue (1989) deu-se através de cortes a mão livre (transversais e paradérmicos) ao nível do terço médio inferior das folhas, bem como por trituração em almofariz de folhas inteiras, pelos detalhes histológicos que esse procedimento pode revelar (Oliveira 
\& Akisue, 1989). A seguir, efetuou-se clareamento desses materiais com solução comercial de hipoclorito de sódio (cândida) e colorações com solução de lugol e de floroglucina cloridrica, alternadamente, preparadas conforme a Farmacopéia Brasileira (1929). Os equipamentos empregados foram: microscópio ótico Leitz com aumentos de 100,250 e 400 vezes, para interpretação dos elementos histológicos; câmara clara e régua micrométrica para a elaboração dos desenhos e mensuração desses elementos (Sass, 1940).

\section{RESULTADOS E DISCUSSÃO}

As folhas das mirtáceas estudadas neste trabalho são simples e hipoestomáticas, com estômatos do tipo ranunculáceo, embora o tipo paracítico seja o mais frequente para a familia (Metcalfe \& Chalk, 1950).

As folhas de Eugenia punicifolia têm contorno predominantemente oboval, enquanto que as de Eugenia cf punicifolia são sempre elipticas (Figs. 1.1, 1.2). As duas espécies de Myrcia descritas também apresentaram contorno foliar elíptico (Figs. 1.3, 1.4).

$\mathrm{O}$ exame microscópico revelouse insuficiente para a distinção entre as plantas do táxon Eugenia aqui estudadas (Figs. 2.1, 2.2): células epidérmicas de contorno onduloso, recobertas por cutícula estriada, em secção paradérmica (Figs. 2.1a, 2.2a); nervuras medianas plano-convexas com feixes bicolaterais envoltos por bainha esclerenquimática (Figs. 2.1d, $2.2 \mathrm{~d}$ ); esporádica presença de cristais dos tipos drusa e cristais prismáticos. A única distinção histológica observada refere-se ao número de camadas do parênquima paliçádico: Eugenia punicifolia revelou duas camadas de parênquima paliçádico e Eugenia cf punicifolia apresentou apenas uma camada de parênquima paliçádico (Figs. 2.1c, 2.2c) Somente estudos conjuntos com quimicos e taxonomistas permitiriam definir conclusivamente se estão sendo observadas variedades da mesma espécie ou espécies diferentes do gênero Eugenia.

As Myrcias, contudo, são histologicamente bem diferentes entre si, o que torna ágil e seguro o reconhecimento de substituições entre as folhas de Myrcia guianensis e Myrcia sphaerocarpa através de exame microscópico, caracteristicamente rápido e econômico (Figs. 2.3, 2.4).

As células epidérmicas de Myrcia guianensis têm contorno onduloso, com paredes anticlinais fortemente espessadas em forma de "rosário" (Figs. 2.3a, 2.3b). Por outro lado, as células epidérmicas de Myrcia multiflora apresentam paredes retas, perfazendo contornos poligonais (Figs. $2.4 \mathrm{a}, 2.4 \mathrm{~b})$. O mesofilo é do tipo dorsiventral, com uma camada de parênquima paliçádico em Myrcia guianensis (Figura 2.3c) e três camadas em Myrcia sphaerocarpa (Fig. 2.4c).

A presença de cristais de oxalato de cálcio é esporádica em Myrcia guianensis e abundante em Myrcia 


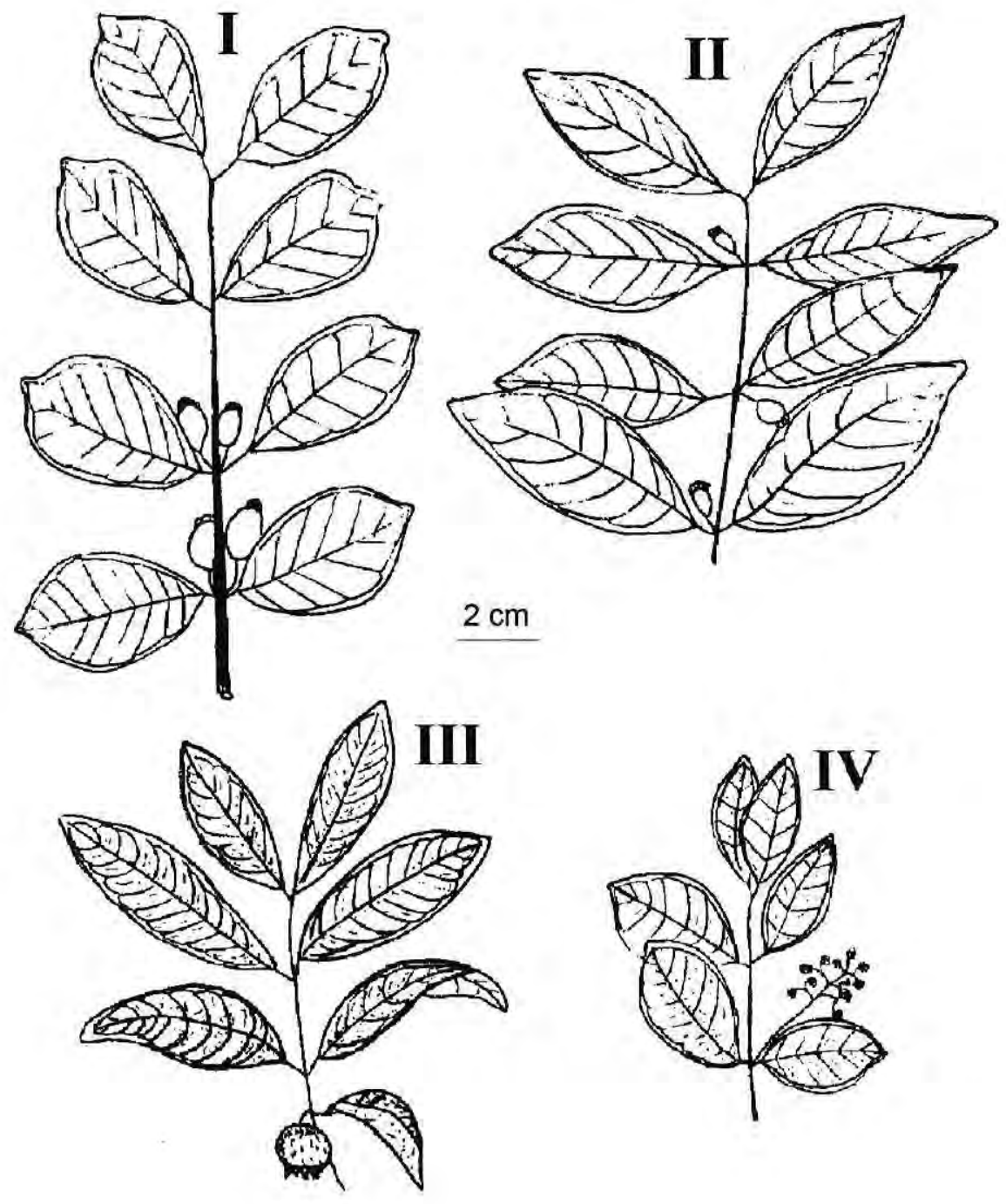

Figura 1. Ramos vegetativos de: I - Eugenia punicifolia (H.B.K.) DC.; II - Eugenia (cf) punicifolia (H.B.K.) DC.; III - Myrcia guianensis (Aubl.) Urb.; IV - Myrcia multiflora (Lam.) DC. ou Myrcia sphaerocarpa $\mathrm{DC}$. 

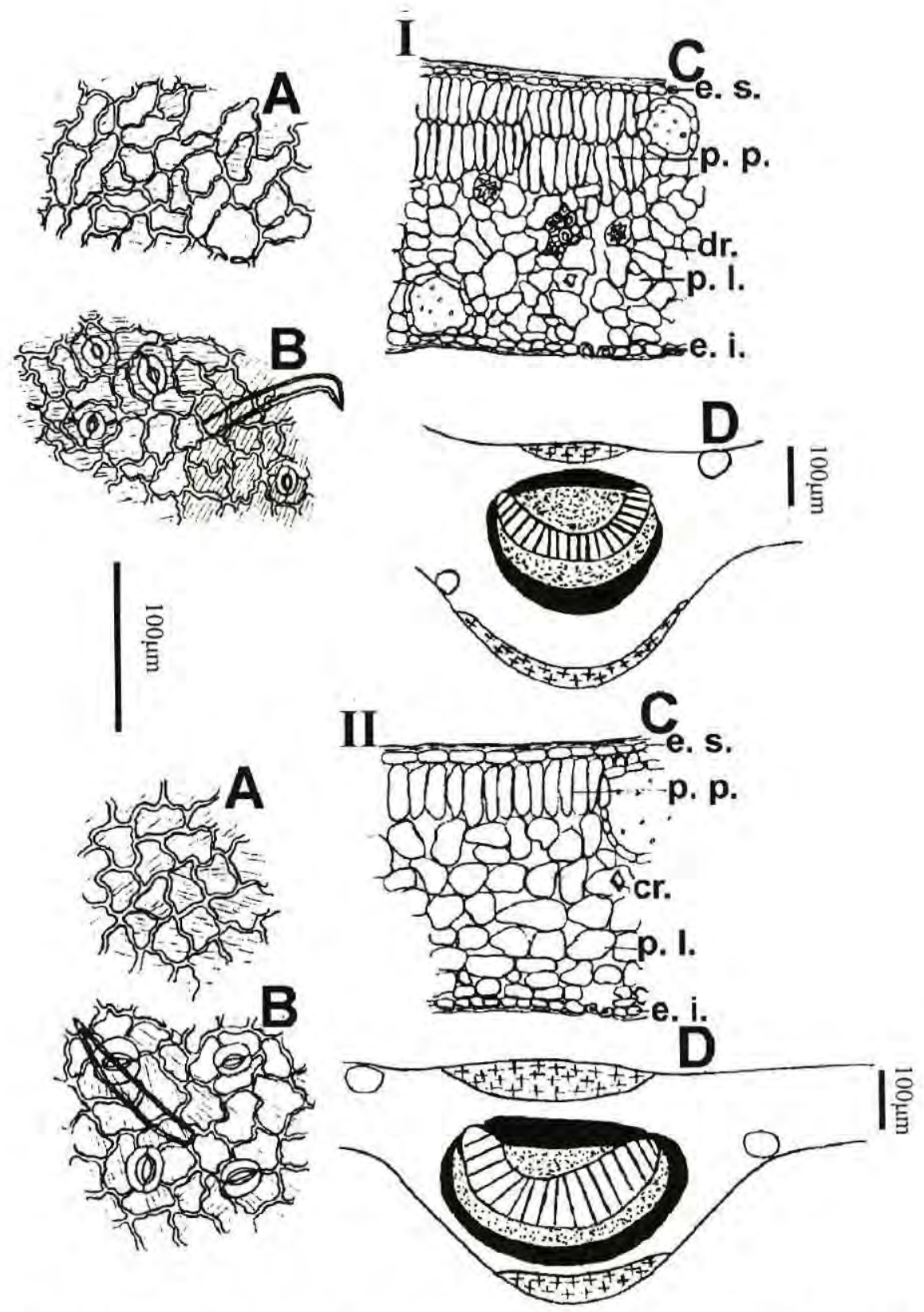

Figura 2. Elementos histológicos foliares diagnósticos de: I - Eugenia punicifolia (H.B.K.) DC.; II - Eugenia (cf) punicifolia (H.B.K.) DC.; III - Myrcia guianensis (Aubl.) Urb.; IV - Myrcia multiflora (Lam.) DC. Sendo: A. Epiderme da face adaxial (superior); B. Epiderme da face abaxial (inferior); C. Mesofilo em corte transversal: e.s. = epiderme da face superior; p.p.= parênquima paliçádico; $\mathrm{p} . \mathrm{l} .=$ parênquima lacunoso; $\mathrm{cr}=$ cristais; $\mathrm{dr}=\mathrm{drusas} ; \mathrm{e} . \mathrm{i} .=$ epiderme da facc inferior; D. Nervura central em secção transversal (desenho esquemático): $++=$ colênquima; $111=$ xilema; $1=$ esclerênquima; $0=$ glândulas oleiferas. 


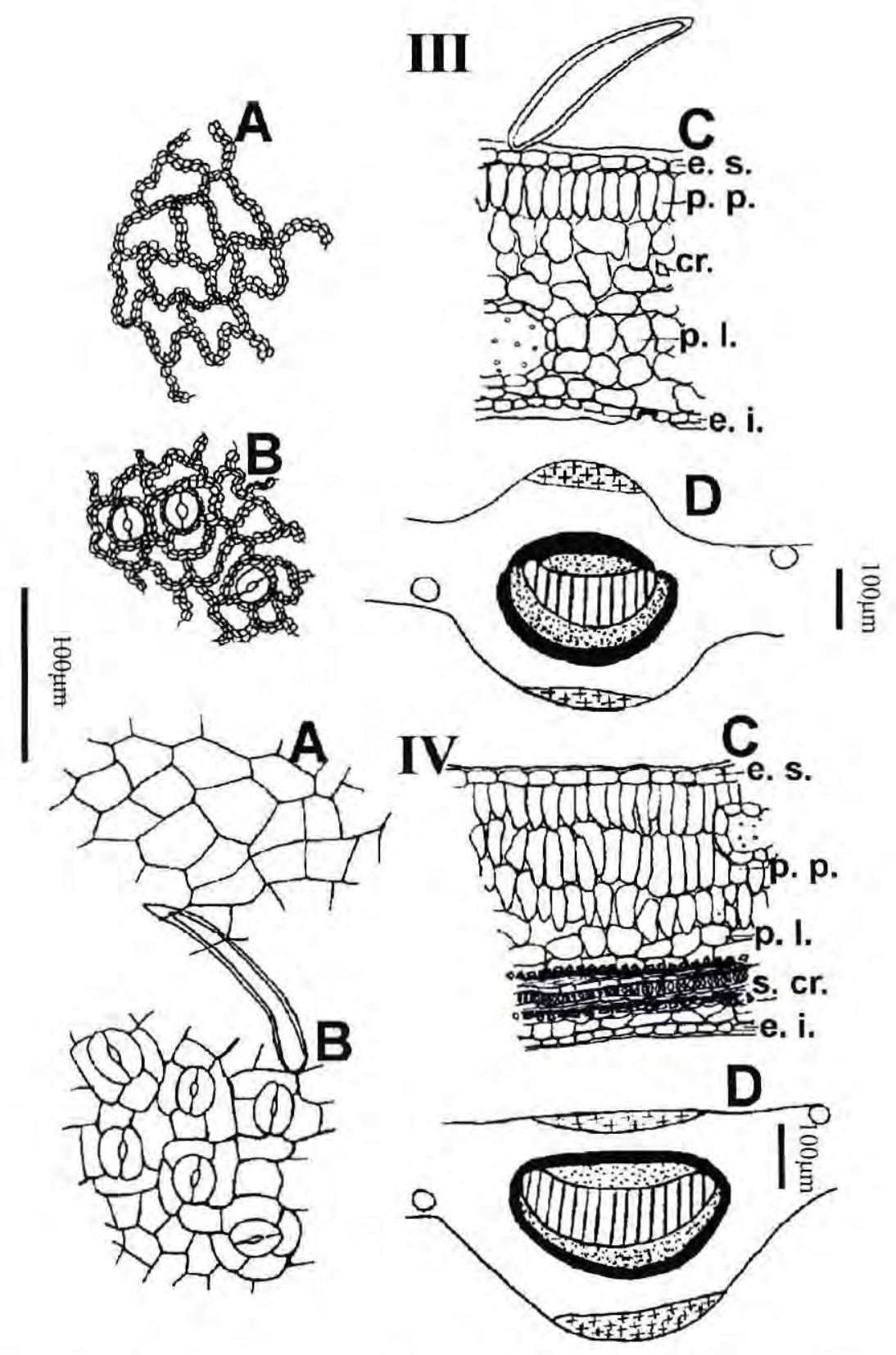

Figura 2. cont. III - Myrcia guianensis (Aubl.) Urb.; IV - Myrcia multiflora (Lam.) DC. Sendo; A. Epiderme da face adaxial (superior); B. Epiderme da face abaxial (inferior); C. Mesofilo em corte transversal: e.s. $=$ epiderme da face superior; p.p.= parênquima paliçádico; p.I.= parênquima lacunoso; $\mathrm{cr}=$ cristais; $\mathrm{dr}=$ drusas; e. $\mathrm{i} .=$ epiderme da face inferior; $\mathrm{D}$. Nervura central em secção transversal (desenho esquemático): $++=$ colênquima; $111=$ xilema; $l=$ esclerênquima; $0=$ glândulas oleiferas. 
multiflora, formando séries cristaliferas ao longo dos feixes vasculares nesta espécie (Figs. 2.3a, 2.4c). A nervura central é bi-convexa em Myrcia guianensis e planoconvexa em Myrcia multiflora (Figs. 2.3d, 2.4d).

As espécies aqui estudadas apresentam as caracteristicas histológicas universais para a familia Myrtaceae: presença de glândulas oleiferas de localização subepidérmica, presença de tricomas tectores simples de formato cônico, dorsiventralidade foliar, hipoestomatismo, presença de bainha esclerenquimática em torno dos feixes vasculares, ocorrência de cristais de oxalato de cálcio no mesofilo e presença de feixes vasculares do tipo bicolateral nas nervuras de maior porte (Metcalfe \& Chalk,1950, citados por Jorge et al., 1994, 1996). A presença de estômatos do tipo anomocítico observada nas mirtáceas, apesar de não ser universal para a família, não chega a constituir casos de exceção, uma vez que esse tipo de estômato é também relatado para os gêneros Paivaea e Plinia (Jorge et al., 1992).

$$
\text { Villaça \& Ferri }
$$
apresentam esquema tridimensional de estrutura "em telefone" que as células estomáticas foliares de diversas mirtáceas apresentam. Esse tipo de estômato não apresenta peculiaridades quando observado rigorosamente em vista facial. Somente cortes paradérmicos profundos ou cortes transversais-longitudinais permitem observar o arranjo "em telefone", à semelhança das gramíneas e das ciperáceas. As espécies estudadas nesse trabalho não apresentam esse arranjo. Incluímos a discussão desse item por sua singularidade no reino vegetal e, ao mesmo tempo, representatividade para as mirtáceas.

\section{CONCLUSÕES}

Embora apresentem as caracteristicas gerais das Myrtaceae (Jorge et al., 1992; 1994; 1996) as espécies aqui estudadas também revelam peculiaridades histológicas que permitem seu reconhecimento mesmo quando não há disponibilidade de ramos vegetativos e/ou floriferos, tais como: contornos celulares epidérmicos, ornamentações de paredes epidérmicas e de cutículas, contorno de nervura central, número de camadas do parênquima paliçádico e frequencia relativa de inclusões celulares.

As células epidérmicas de Eugenia são recobertas por cuticula estriada, caracteristica suficiente para separar esse gênero de Myrcia, cujas espécies apresentam folhas recobertas por cuticula lisa. A separação entre Myrcia guianensis e Myrcia sphaerocarpa é farta e seguramente obtida através dos seus respectivos elementos histológicos:

1-Myrcia guianensis

- Paredes celulares epidérmicas ondulosas e ornamentadas " em rosário" em vista facial.

- Parênquima paliçádico constituido de apenas uma camada de células. 
- Escassa presença de cristais isolados de oxalato de cálcio.

- Nervura central de contorno côncavo-convexo no corte transversal.

2- Myrcia sphaerocarpa

- Paredes celulares epidérmicas retas e lisas.

- Parênquima paliçádico constituido de três camadas de células.

- Abundante ocorrência de cristais de oxalato de cálcio, isolados e em séries cristaliferas.

- Nervura central de contorno plano-convexo no corte transversal.

\section{AGRADECIMENTOS}

\section{Agradecemos às Doutoras Lúcia} Rossi e Maria Lúcia Kawasaki, taxonomistas do Herbário do Instituto de Botânica, São Paulo, SP, pela identificação das espécies estudadas neste trabalho, bem como pelas sugestões apresentadas.

\section{Bibliografia citada}

Almeida, E.R. 1993. Plantas medicinais brasileiras. Hemus Ltda., São Paulo. p.289-90.

Barroso, G.M.1984. Sistemática de angiospermas do Brasil v.2. Imprensa Universitária, Universidade Federal de Viçosa, Viçosa. p.114-120.

Conceição, M. 1982. As plantas medicinais do ano 2000. $2^{\circ}$ ed. TAO Ltda, São Paulo. 111p.

Cruz, G.L. 1982. Dicionário das plantas úteis do Brasil. $2^{\circ}$ ed. Civilização Brasileira, Rio de Janeiro. 498p.

Farmacopéia dos Estados Unidos do Brasil. 1929. Nacional, São Paulo, p.1020-1085.

Foster, A.S.; Gifford Jr., E.M. 1974, Comparative morphology of vascular plants. $2^{\circ} \mathrm{ed}$. W. H. Freeman \& Company, S. Francisco.
$387 \mathrm{p}$.

Hecht, S.M. 1984. Biologically active extracts from Myrcia fallax (Myrtaceae) Peru, apud. Chem. Abstr., 101p.

Jorge, L.I.F. 1992. Caracterização farmacobotänica e microscopia alimentar de seis es-pécies brasileiras de Myrtaceae. Jussieu. Tese de mestrado, Faculdade de Ciências Farmacêuticas da Universidade de São Paulo, São Paulo.

Jorge, L.I.F.; Markman, B.E.; Silva, C.B.M. 1994. Jambolào: Syzygium cumini (L.) Skeels Elementos histológicos caracteristicos das folhas, frutos e cascas. Rev. Bras. Farm., 75(2):38-39.

Jorge, L.I.F.; Ferro, V.O.; Oliveira, I. 1996. Exame diagnóstico das folhas e frutos de Plinia glomerata (cabeludinha) e Eugenia pyriformis (uvalha). Rev. Bras. Farm., 77(1):7-10.

Martins de Toledo, O. 1929. Pedra-hume-caá - ação hipoglicemiante. Tese de doutoramento Faculdade de Medicina de São Paulo, São Paulo.

Maruzzella, J.C.; Henry, P.A. 1958. Antimicrobial activity of perfume oils. J. Am. Pharm. Assoc., 47:471-476.

Mendes dos Reis Arruda, L.F.; Castro da Costa, P. R. 1978. Efeito hipoglicemiante induzido pelo extrato farmacológico preliminar. $\mathrm{V}$ Simpósio de plantas medicinais do Brasil, 4 a 6 de setembro, Escola Paulista de Medicina, São Paulo. p.74.

Mors, W.B.; Grune, U. 1978. Myrcia sphaerocarpa DC. Planta diabética. V Simpósio de plantas medicinais do Brasil, 4 a 6 de setembro, Escola Paulista de Medicina, São Paulo. p.72.

Nadal, N.G.M. 1959. Nonterpenic fraction of Puerto Rican bay oil, Myrcia acris. Am. Perfumer Aromat., 73(6):22-24.

Oliveira, F; Saito, M.L. 1991. Práticas de morfologia vegetal. Livraria Atheneu, Rio de Janeiro e São Paulo. 187p.

Pio Correa, M. 1926. Dicionário das plantas úteis do Brasil e das exóticas cultivadas. v.1 pt 2 Ministério da Agricultura, Rio de 
Janeiro, p.422.

Sass, J.E. 1940. Elements of botanical microtechnique. McGraw-Hill, New York. $165 \mathrm{p}$.

Villaça, H.; Ferri, M.G. 1954. On the morphology of the stomata of Eucaliptus tereticornis, Ouratea spectabilis and Cedrella fissilis. Bol. Fac. Fil. Let., 12:31-51. 